\title{
FORMULASI SABUN PEMBERSIH KEWANITAAN (Feminime Hygiene) DARI MINYAK ATSIRI RIMPANG LENGKUAS PUTIH (Alpinia galanga L) DAN UJI AKTIFITAS ANTISEPTIK TERHADAP Candida albicans
}

\author{
Wida Ningsih $^{1 *)}$, Diana Agustin ${ }^{2)}$, Putri Sefrianti ${ }^{2)}$ \\ ${ }^{1)}$ Progaram Studi Farmasi, Fakultas Sains dan Teknologi, Universitas Muhammadiyah Sumatera \\ Barat \\ ${ }^{2)}$ Sekolah Tinggi Farmasi Indonesia Padang \\ *Email nwida777@gmail.com
}

\section{INTISARI}

Candida albicans merupakan flora normal pada genitalia wanita yang dapat menyebabkan keputihan. Rimpang lengkuas putih mengandung minyak atsiri eugenol yang memiliki aktifitas menghambat pertumbuhan Candida albicans. Penelitian ini memformulasi minyak atsiri rimpang lengkuas putih dalam bentuk sabun pembersih kewanitaan (feminime hygiene) agar memudahkan dan memberi kenyamanan saat penggunaan dan untuk mengetahui aktivitas antiseptik feminime hygiene dari minyak atisri rimpang lengkuas putih terhadap Candida albicans.

Minyak atsiri rimpang lengkuas putih diformulasi dalam tiga variasi konsentrasi yaitu $10 \%$, $15 \%$ dan $20 \%$. Feminime hygiene minyak atsiri rimpang lengkuas putih dilakukan evaluasi seperti organoleptis, homogenitas, bobot jenis, uji daya busa, viskositas, $\mathrm{pH}$ dan stabilitas. Pengujian aktivitas antiseptik diujikan dengan media SDA (Sabouraud Dextrose Agar) dan menggunakan metode difusi agar.

Hasil evaluasi feminime hygiene yang diformulasi menunjukan hasil yang hampir sama dengan hasil evaluasi pembanding (BN). Parameter adanya aktivitas antiseptik ditunjukkan dengan terbentuknya diameter zona hambat dimana F0(kontrol negatif), F1(10\%), F2(15\%), dan F3(20\% ) secara berurutan mempunyai nilai diameter rata-rata $11 \mathrm{~mm}, 14,65 \mathrm{~mm} \mathrm{17,58} \mathrm{mm}$ dan 25,41 $\mathrm{mm}$. Kategori klasifikasi respon hambatan pertumbuhan mikroba menurut CLSI, F0 dan F1 termasuk golongan lemah, F2 golongan sedang dan F3 golongan kuat. Berdasarkan hasil analisis statistik ANOVA satu arah terdapat perbedaan yang bermakna pada sediaan sabun cair F0, F1, F2 dengan F3 pada $(\mathrm{P}<0,05)$. Minyak atsiri rimpang lengkuas putih dapat diformulasi menjadi sabun pembersih kewanitaan (feminime hygiene) dan memiliki aktivitas antiseptik terhadap jamur Candida albicans penyebab keputihan.

Kata kunci : lengkuas putih, antiseptik, candida albicans

\section{ABSTRACT}

Candida albicans is a normal flora in the female genitalia which can cause vaginal discharge. White galangal rhizome contains essential oils of eugenol which have activities that inhibit the growth of Candida albicans. This study formulated the white galangal rhizome essential oil in the form of feminime hygiene to make it easier and more comfortable to use and to determine the antiseptic feminime hygiene activity of the white galangal rhizome oil of Candida albicans.

The essential oil of white galangal rhizome is formulated in three variations of concentration namely 10\%, 15\% and 20\%. Feminime hygiene of essential white galangal rhizome oil was evaluated such as organoleptic, homogeneity, specific gravity, foam power test, viscosity, $p H$ and 
stability. Antiseptic activity testing was tested with SDA (Sabouraud Dextrose Agar) media and using agar diffusion method.

The results of the feminime hygiene evaluation formulated showed results similar to the results of comparative evaluations $(B N)$. The parameters of antiseptic activity are indicated by the formation of inhibitory zone diameters where FO (negative control), F1 (10\%), F2 (15\%), and F3 (20\%) respectively have an average diameter value of $11 \mathrm{~mm}, 14.65 \mathrm{~mm} 17.58 \mathrm{~mm}$ and $25.41 \mathrm{~mm}$. The classification category of the response to microbial growth according to CLSI, FO and FI includes the weak group, the F2 is the moderate group and the F3 is the strong group. Based on the results of one-way ANOVA statistical analysis there were significant differences in liquid soap preparations FO, F1, F2 with F3 at $(P<0.05)$. White galangal rhizome essential oil can be formulated into feminine hygiene and has antiseptic activity against the fungus Candida albicans.

Keywords: white galangal, antiseptic, candida albicans

*Corresponding author:

Wida Ningsih

Program Studi Farmasi, Fakultas Sains dan Teknologi, Universitas Muhammadiyah Sumatera Barat email: nwida777@gmail.com

\section{PENDAHULUAN}

Kebersihan daerah kewanitaan bagi perempuan sangat penting karena dapat membuat wanita merasa nyaman dan dapat mencegah dari penyakit serta infeksi menular (Taylor, 2000). Salah satu penyakit yang diderita oleh wanita pada daerah kewanitaan adalah keputihan yang merupakan infeksi jamur pada genitalia wanita disebabkan oleh organisme jamur yaitu Candida albicans (Clayton, 1998). Telah dilaporkan bahwa Candida sp merupakan jamur yang paling banyak ditemukan pada sekret vagina wanita yang mengalami keputihan. Dari 100 spesies Candida yang berhasil diisolasi, 50-60\% nya adalah Candida albicans yang merupakan flora normal selaput mukosa, saluran pernapasan, saluran pencernaan dan genitalia wanita. Namun jamur ini diketahui merupakan spesies Candida yang paling berbahaya. Dilaporkan bahwa 85-95\% penyebab keputihan adalah Candida albicans (Wozniak dkk., 2002). Rimpang lengkuas putih mengandung metabolit sekunder minyak atsiri seperti eugenol yang mempunyai aktifitas antijamur (Erna, 2005) terhadap Candida albicans (Utami dan Wahyuni, 2010). Minyak atsiri rimpang lengkuas putih (Alpinia galanga, L.) yang mengandung eugenol dengan konsentrasi $8 \%, 11 \%$ dan $14 \%$ mempunyai efek menghambat pertumbuhan Candida albicans. Pada konsentrasi minyak atsiri lengkuas putih $8 \%$, menghasilkan diameter daya hambat $8,7 \mathrm{~mm}$, diameter daya hambat dengan konsentrasi $11 \%$ adalah $8,9 \mathrm{~mm}$ dan pada konsentrasi $14 \%$ diameter daya hambatnya yaitu $9,2 \mathrm{~mm}$. Dari hasil diameter daya hambat ini dapat dilihat kategori klasifikasi respon hambat berdasarkan Clinical and Laboratory Standart Institute (CLSI), respon hambat pertumbuhannya dikategorikan lemah (Cockerill dkk., 2012). Jamur Candida albicans merupakan jamur yang dapat dihambat pertumbuhannya dengan sediaan antiseptik. Sediaan antiseptik berisi zat aktif yang biasa digunakan untuk menghambat pertumbuhan atau membunuh mikroorganisme yang hidup di permukaan tubuh (Sari dan Isadiartuti, 2006).

Sabun pembersih kewanitaan (feminime hygiene) adalah suatu sediaan pembersih daerah kewanitaan berbentuk cair yang dibuat dari bahan dasar dan digunakan untuk membersihkan daerah kewanitaan tanpa menimbulkan iritasi pada kulit (Rahmi dkk., 2017). Sabun cair ini banyak diproduksi karena penggunaanya yang lebih praktis, bentuk yang menarik, aman jika digunakan secara berulang. Di samping itu sabun cair dapat digunakan sebagai antiseptik terhadap bakteri dan jamur, sehingga dapat mengurangi kemungkinan terserang infeksi yang disebabkan oleh bakteri dan jamur. Penelitian ini bertujuan untuk memformulasi sabun cair antiseptik yang mengandung minyak atsiri rimpang lengkuas putih dengan konsentrasi 10\%, 15\% dan 20\% untuk mengatasi jamur Candida albicans penyebab keputihan.

JIFFK Vol. 16, No. 1, JUNI 2019, Hal. 51 - 58 


\section{METODE PENELITIAN}

\section{Bahan dan Alat}

1. Bahan

Gelas ukur $\left(\right.$ Pyrex $\left.^{\circledR}\right)$, corong (Enaco), cawan petri, tabung reaksi (Iwaki ${ }^{\circledR}$ ), rak tabung reaksi, erlenmeyer (Iwaki ${ }^{\circledR}$ ), penjepit, pinset, batang pengaduk, pipet tetes, inkubator, LAF (Laminar Air Flow), autoklaf (All American), lampu spiritus, jarum ose, kapas steril (Sari bunga), lumpang, alu, sudip, pot salap, timbangan analitik (Adventurer), kaca objek, $\mathrm{pH}$ meter (HAQ), piknometer $\left(\right.$ Pyrex $\left.^{\circledR}\right)$, pisau, botol semprot, refraktometer Abbe, lemari pendingin (Panasonic), pipet mikron (Baeco), oven (Memmert), mikroskop (Iscope), kaca objek dan vortex (Baeco), autoklaf (Memmert).

\section{Alat}

Minyak atsiri lengkuas putih (PT.Lansida), Jamur Candida albicans, SDA (Sabouraud Dextrose Agar) (Mereck), Sodium Lauril Sulfat (Harum Kimia), NaCl (Harum Kimia), Propilenglikol (Harum Kimia), Asam Sitrat (Harum Kimia), Aquadest (Brataco), Cocoamidopropylbetaine (Brataco), $\mathrm{NaCl}$ fisiologis (Widatra Bhakti), sabun yang beredar (Bio Natural), DMSO (Merck), Gentian Violet (Merck), Alkohol 96\% (Brataco), Lugol (Brataco) dan Fuchsin (Mutiara).

\section{Pembuatan Sabun Cair Minyak atsiri Rimpang Lengkuas Putih}

Empat formula sabun cair dibuat sesuai formula yang tercantum pada tabel I. Semua bahan ditimbang sesuai Tabel I.

Tabel I. Formula Sabun Cair (Mutmainah dan Franyoto, 2015)

\begin{tabular}{lcccc}
\hline \multicolumn{1}{c}{ Komposisi } & F0 (\%) & F1(\%) & F2 (\%) & F3(\%) \\
\hline Minyak atsiri rimpang lengkuas putih & - & 10 & 15 & 20 \\
Sodium Lauril Sulfat & 18,5 & 18,5 & 18,5 & 18,5 \\
$\mathrm{NaCl}$ & 5 & 5 & 5 & 5 \\
Propilenglikol & 1 & 1 & 1 & 1 \\
Asam Sitrat & 0,5 & 0,5 & 0,5 & 0,5 \\
Cocoamidopropylbetaine & 5 & 5 & 5 & 5 \\
Air suling ad & 100 & 100 & 100 & 100 \\
\hline
\end{tabular}

Sodium Lauril Sulfat dimasukkan ke dalam wadah, lalu dilarutkan dengan air panas hingga larut terbentuk M1. Asam sitrat dilarutkan dengan air suling hingga larut dengan wadah yang berbeda terbentuk $\mathrm{M} 2$. $\mathrm{NaCl}$ dilarutkan dengan air hingga larut di dalam wadah yang berbeda terbentuk M3. Kemudian M1 ditambahkan Cocoamidopropylbetaine dan diaduk hingga bercampur homogen, lalu dimasukkan minyak atsiri lengkuas putih dan diaduk kembali, setelah itu ditambahkan campuran M2 dan diaduk hingga bercampur homogen, diambil propilenglikol dan dimasukkan sambil diaduk, M3 dimasukkan secara perlahan dan diaduk sampai terbentuk massa sabun cair. Setelah semua tercampur dicukupkan dengan aquadest hingga $100 \mathrm{~mL}$.

\section{Evaluasi Formula Sabun Cair dan Pembanding \\ 1. Pemeriksaan organoleptis}

Pengamatan terhadap bentuk, bau dan warna dilakukan secara visual dan diamati tiap minggu selama 8 minggu (Depkes RI, 1979).

\section{Pemeriksaan homogenitas}

Sabun cair ditimbang 0,1 g kemudian dioleskan pada kaca objek, sediaan harus menunjukkan susunan yang homogen dan tidak terlihat adanya butiran kasar, diamati tiap minggu selama 8 minggu (Ditjen POM, 1985).

\section{Pemeriksaan bobot jenis}

Menentukan bobot jenis sabun cair dilakukan dengan menggunakan piknometer kosong, bersih, kering. Cara: diambil piknometer yang sudah diketahui volumenya yaitu (a). Berat piknometer tersebut dinyatakan dengan nilai (b). Piknometer diisi dengan sabun cair minyak atsiri 
rimpang lengkuas putih dan ditimbang, beratnya dinyatakan dengan nilai (c), dipastikan tidak ada rongga udara pada tutup piknometer (Depkes RI, 1995 dan Guenther, 1987) dan diamati setiap minggu selama 8 minggu.

$$
\begin{aligned}
& \text { Rumus } \quad B J=\frac{c-b}{a} \\
& \text { Keterangan: } \\
& \mathrm{Bj}=\text { Berat jenis minyak }(\mathrm{g} / \mathrm{mL}) \\
& \mathrm{a}=\text { Volume piknometer }(\mathrm{mL}) \\
& \mathrm{b}=\text { Berat piknometer kosong }(\mathrm{g}) \\
& \mathrm{c}=\text { Berat piknometer kosong + sabun cair minyak atsiri lengkuas putih }(\mathrm{g})
\end{aligned}
$$

\section{Pemeriksaan daya busa}

Mengukur tinggi dari larutan sabun cair yang diaduk dengan kecepatan tertentu menggunakan magnetic stirrer. Cara: dimasukkan $1 \mathrm{~g}$ sabun cair dalam beaker glass, ditambahkan $10 \mathrm{~mL}$ air suling. Diaduk dengan magnetic stirrer pada kecepatan 600 RPM selama lebih kurang 2 menit. Diukur tinggi busa yang terbentuk dan diamati tiap minggu selama 8 minggu (Poucher, 1993).

\section{Pemeriksaan viskositas}

Alat yang digunakan ialah viskometer Brookfield. Sediaan sabun cair dimasukkan ke dalam gelas beker $500 \mathrm{~mL}$. Pengukuran dilakukan dengan viskometer Brookfield, spindel dicelupkan ke dalam sediaan sabun cair sampai garis tanda batas yang ada pada spindel, kemudian alat dinyalakan. Pemeriksaan dilakukan pada minggu pertama dan minggu ke-8 (Lachman dkk., 1994).

\section{Pemeriksaan pH}

Pemeriksaan ini dilakukan dengan menggunakan alat $\mathrm{pH}$ meter. Alat ini dikalibrasi terlebih dahulu dengan menggunakan larutan dapar asetat $\mathrm{pH}$ 4,0 dan dapar fosfat $\mathrm{pH}$ 7,0 sehingga posisi jarum alat menunjukkan harga $\mathrm{pH}$ tersebut. Elektroda dibilas dengan air suling dan dikeringkan. Pengukuran $\mathrm{pH}$ sabun cair dilakukan dengan cara elektroda dicelupkan dalam wadah tersebut. Dibiarkan angka bergerak pada posisi konstan. Angka yang ditunjukkan oleh $\mathrm{pH}$ meter merupakan nilai $\mathrm{pH}$ sediaan tersebut dan diamati setiap minggu selama 8 minggu (Depkes RI, 1995).

\section{Cycling test}

Sediaan disimpan pada suhu dingin $\left(4 \pm 2^{\circ} \mathrm{C}\right)$ selama 24 jam, lalu dipindahkan ke dalam oven yang bersuhu $40 \pm 2^{\circ} \mathrm{C}$ selama 24 jam. Perlakuan ini disebut 1 siklus. Pengujian dilakukan sebanyak 6 siklus dan diamati terjadinya perubahan fisik sabun cair (bentuk, warna, bau dan pemisahan fase) (Djajadisastra, 2004).

\section{Pengujian Aktivitas Antijamur}

\section{Identifikasi jamur Candida albicans}

Diambil kaca objek, lalu kaca objek dibersihkan dengan menggunakan alkohol, lalu dikeringkan dengan cara diangin-anginkan pada api, kaca objek yang telah disterilkan ditetesi aquadest, diambil koloni jamur dengan menggunakan jarum ose yang telah dibakar dengan api sampai merah, lalu koloni dioleskan pada kaca objek yang telah ditetesi aquadest, diaduk-aduk sampai homogen, kemudian dikering anginkan pada api, sampai aquadest kering, ditetesi dengan gentian violet sebanyak 2 tetes dan didiamkan selama 1- 2 menit. Dicuci dengan menggunakan air mengalir, seterusnya ditetesi lugol dan didiamkan selama 1 menit, kemudian dicuci dengan menggunakan air mengalir. Dicelupkan ke dalam alkohol 96\% dan didiamkan selama 30 detik, setelah itu ditetesi air fuchsin sebanyak 1 tetes dan didiamkan selama 2 menit, diamati di bawah mikroskop dengan perbesaran 100 kali (Purwoko dan Tjahjadi, 2010).

\section{Preparasi media}

Media yang digunakan adalah Sabouraud Dextrose Agar (SDA) sebanyak 6,5 g dilarutkan ke dalam $100 \mathrm{~mL}$ aquadest. Kemudian dipanaskan di atas hot plate sampai media tersebut mendidih dan homogen kemudian disterilkan terlebih dahulu dengan autoklaf pada suhu $121{ }^{\circ} \mathrm{C}$ selama 15 menit dengan tekanan $15 \mathrm{lbs}$ dan dibiarkan dingin sampai suhu $45-50^{\circ} \mathrm{C}($ Pangalinan dkk., 2011). 


\section{Pembuatan suspensi mikroba uji}

Pembuatan suspensi jamur Candida albicans dilakukan dengan cara jamur Candida albicans diambil 2 jarum ose dan dilarutkan dengan $1 \mathrm{~mL} \mathrm{NaCl}$ fisiologis dan terbentuklah larutan induk, dari larutan induk ini diambil $100 \mu \mathrm{L}$ lalu dimasukkan ke dalam tabung reaksi yang berisi $900 \mu \mathrm{L}$ $\mathrm{NaCl}$ fisiologis steril sehingga diperoleh pengenceran $10^{-1}$. Kemudian, dari pengenceran $10^{1}$ diambil $100 \mu \mathrm{L}$ larutan dimasukkan ke tabung reaksi yang berisi $900 \mu \mathrm{L} \mathrm{NaCl}$ fisiologis steril sehingga diperoleh pengenceran $10^{-2} \mathrm{kali}$. Demikian seterusnya sehingga diperoleh pengenceran sampai $10^{-4} \mathrm{kali}$. Suspensi Candida albicans yang digunakan sebagai dasar pengujian spesimen pada penelitian ini adalah pengenceran $10^{-4}$ kali (Atmaja, 2007).

\section{Pengujian aktivitas antiseptik sabun cair}

Sebanyak $20 \mathrm{~mL}$ media SDA dimasukkan ke dalam cawan petri kemudian ditambahkan 1 $\mathrm{mL}$ suspensi jamur pada pengenceran $10^{-4}$ lalu dihomogenkan dan dibiarkan memadat. Ditimbang sebanyak 1 gram F0 (sabun cair tanpa minyak atsiri) F1, F2 dan F3 kemudian diencerkan dengan DMSO hingga $2 \mathrm{~mL}$. Lalu kertas cakram steril diletakkan ke dalam cawan petri. Setelah itu dipipet sebanyak $10 \mu \mathrm{L}$ tiap formula yang telah diencerkan dengan DMSO, diteteskan di atas kertas cakram steril sedangkan sabun cair pembanding BN langsung dipipet sebanyak $10 \mu \mathrm{L}$ tanpa diencerkan dengan DMSO. Cawan petri yang berisi kertas cakram yang diberi sampel uji lalu diinkubasi pada suhu $37{ }^{\circ} \mathrm{C}$ selama 72 jam di dalam inkubator dengan posisi cawan petri dibalikkan. Pengamatan pertumbuhan jamur dengan cara diukur diameter daya hambat jamur yang ditandai adanya daerah bening di sekeliling kertas cakram. Pengujian masing-masing sampel uji dilakukan sebanyak 3 pengulangan.

\section{Analisis data}

Data hasil pengujian aktivitas antiseptik minyak atsiri rimpang lengkuas putih dalam sediaan sabun cair diolah secara statistik dengan analisis ANOVA satu arah.

\section{HASIL DAN PEMBAHASAN}

Penelitian ini bertujuan untuk memformulasi minyak atsiri rimpang lengkuas putih dalam sediaan sabun feminime hygiene sebagai antiseptik. Lengkuas putih mengandung minyak atsiri yang memiliki aktivitas biologis yang dapat menghambat pertumbuhan jamur. Kand ungan rimpang lengkuas putih mengandung minyak atsiri yang memiliki sifat sebagai antijamur yaitu eugenol (Erna, 2005), dan memiliki aktivitas terhadap Candida albicans (Utami dan Wahyuni, 2010). Minyak atsiri rimpang lengkuas putih yang digunakan pada penelitian ini diperoleh dari PT. Lansida, Yogyakarta.

Minyak atsiri rimpang lengkuas putih digunakan pada formula feminime hygiene dengan konsentrasi 10\%, 15\% dan 20\%. Pemilihan konsentrasi merujuk kepada penelitian Rahmalia dkk., (2010) yang menyatakan bahwa minyak atsiri rimpang lengkuas putih dengan konsentrasi $8 \%, 11 \%$ dan $14 \%$ mempunyai efek menghambat pertumbuhan jamur Candida albicans. Dari hasil pengukuran diameter daya hambat masih dikategorikan lemah berdasarkan klasifikasi respon hambat Clinical and Laboratory Standard Institute (CLSI) (Cockerill dkk., 2012). Oleh karena itu konsentrasi yang digunakan pada pembuatan sabun cair ditingkatkan menjadi $10 \%, 15 \%$ dan $20 \%$, sehingga diharapkan dapat menghasilkan sediaan sabun cair yang memiliki aktivitas antiseptik terhadap Candida albicans.

Selain minyak atsiri juga digunakan bahan-bahan tambahan lain, yaitu sodium lauril sulfat sebagai surfaktan anionik yang menghasilkan busa, namun busa yang dihasilkan tidak stabil dan mudah pecah, sehingga membutuhkan surfaktan sekunder untuk memperbaiki kualitas busa (Draelos dan Thaman, 2006; Riegar, 2000). NaCl berfungsi dalam proses saponifikasi untuk memisahkan produk sabun dengan gliserin, dan dapat meningkatkan kekentalan pada sabun cair (Draelos dan Thaman, 2006). Propilenglikol digunakan untuk memberikan efek melembabkan kulit, sehingga dapat menghindari kulit menjadi kering (Wilkinson dan Moore, 1982). Asam sitrat adalah asam lemak yang lemah, yang digunakan untuk menetralisasi reaksi basa, sehingga dapat mempertahankan keseimbangan $\mathrm{pH}$ pada daerah yang akan digunakan sabun (Wasitaatmadja, 1997). Cocoamidopropylbetaine adalah surfaktan amfoterik yang dapat memperbaiki fungsi dari 
surfaktan anionik dalam pembusaan (Rieger, 2000)., Dalam penelitian ini digunakan sediaan feminime hygiene yang beredar di pasaran yaitu $\mathrm{BN}^{\circledR}$ sebagai pembanding. Pemilihan sabun cair $\mathrm{BN}^{\circledR}$ didasarkan pada kemasannya yang tercantum dapat menghambat jamur Candia albicans.

Pemeriksaan organoleptis bertujuan untuk melihat tampilan fisik dari suatu sediaan yang meliputi bentuk, warna dan bau. Berdasarkan hasil pemeriksaan organoleptis, sabun cair minyak atsiri rimpang lengkuas putih tidak mengalami perubahan, hal ini mengindikasikan bahwa sediaan sabun cair minyak atsiri rimpang lengkuas putih stabil selama penyimpanan 8 minggu secara fisika.

Pemeriksaan homogenitas sediaan sabun cair minyak atsiri rimpang lengkuas putih dilakukan selama 8 minggu, bertujuan untuk mengetahui komponen sabun cair tercampur merata dalam sediaan. Hasil pemeriksaan yang dilakukan secara visual, menunjukkan bahwa sabun cair minyak atsiri rimpang lengkuas putih homogen, karena tidak adanya terlihat butiran-butiran kasar pada basis dan formula sabun cair minyak atsiri rimpang lengkuas putih.

Pemeriksaan nilai bobot jenis suatu sediaan dilakukan selama 8 minggu, dan dari hasil ratarata nilai bobot jenis formula sabun cair minyak atsiri rimpang lengkuas putih terdapat perbedaan dengan sediaan pembanding. Hal ini dapat dipengaruhi oleh bahan penyusun dan sifat fisiknya (Gaman dan Sherington, 1990). Untuk F1, F2 dan F3 terlihat perbedaan nilai bobot jenis sabun cair yang disebabkan karena perbedaan konsentrasi minyak atsiri rimpang lengkuas putih.

Pengujian tinggi busa bertujuan untuk melihat busa yang dihasilkan. Dari pemeriksaan dapat dilihat bahwa semakin tinggi konsentrasi minyak atsiri rimpang lengkuas putih maka busa yang dihasilkan semakin rendah. Untuk tinggi busa, sediaan pembanding lebih tinggi dibandingkan formula sabun cair.

Pemeriksaan viskositas bertujuan untuk mengetahui konsistensi sediaan yang nantinya akan berpengaruh terhadap pengaplikasian sediaan, seperti mudah dikeluarkan dari wadahnya. Berdasarkan hasil pengamatan diperoleh untuk semua formula sabun cair menunjukkan hasil yang berbeda dengan sabun pembanding, yaitu sabun pembanding secara visual terlihat lebih encer dibandingkan formula sabun cair. Tetapi kekentalan dari formula sabun cair masih mudah dituang dari wadah. Pada minggu ke-8, terjadi penurunan viskositas untuk F1 dan peningkatan viskositas pada F2 dan F3. Peningkatan viskositas berhubungan dengan ukuran partikel selama penyimpanan, yaitu partikel-partikel cenderung memperkecil luas permukaan dengan cara penggabungan antar partikel, sehingga diperoleh partikel yang lebih besar dan luas permukaan yang lebih kecil, sehingga viskositas akan meningkat (Lachman dkk., 1994).

Pemeriksaan $\mathrm{pH}$ dilakukan selama 8 minggu menggunakan $\mathrm{pH}$ meter. Hasil pengamatan didapatkan nilai $\mathrm{pH}$ sabun cair miyak atsiri rimpang lengkuas putih, mengalami perubahan. Perubahan nilai $\mathrm{pH}$ tiap minggu disebabkan oleh faktor lingkungan seperti suhu, lama penyimpanan, dan sensitivitas dari alat $\mathrm{pH}$. Namun dari hasil rata-rata nilai $\mathrm{pH}$ masih berada dalam pH normal vagina yaitu 3-4 (Standar Nasional Indonesia, 1996), sehingga sabun aman digunakan pada vagina.

Pemeriksaan stabilitas sabun cair minyak atsiri rimpang lengkuas putih dilakukan bertujuan untuk melihat kemampuan suatu produk atau kosmetik dapat bertahan dalam waktu penyimpanan yang telah ditetapkan, serta dapat menjamin identitas produk. Dari hasil pemeriksaan tidak adanya perubahan karakteristik fisika selama penyimpanan, hal ini menandakan sabun cair minyak atsiri rimpang lengkuas putih stabil secara fisika selama penyimpanan.

Identifikasi dilakukan pewarnaan Gram menggunakan beberapa reagen yaitu gentian violet, lugol, alkohol 96\%, dan air fuchsin. Gentian violet merupakan pewarna primer yang akan memberikan warna pada mikoorganisme target. Lugol atau merupakan komplek iodine ditambahkan agar pewarna terikat lebih kuat pada sel jamur. Penambahan alkohol $96 \%$ bertujuan untuk memucatkan warna yang menempel pada sel jamur. Air fuchsin merupakan pewarna sekunder yang berfungsi mewarnai sel-sel yang telah kehilangan warna utama (Pelezer, 1998). Hasil identifikasi pewarnaan Gram memberikan warna ungu, yang menunjukkan jamur gram positif dan pengamatan di bawah mikroskop terlihat adanya benang hifa (Siregar, 2004).

Pengujian aktivitas antiseptik sediaan sabun cair minyak atsiri rimpang lengkuas putih terhadap jamur Candida albicans, dilakukan dengan cara F0, F1, F2, dan F3 ditimbang sebanyak 1 gram tiap formula dan diencerkan dengan DMSO hingga $2 \mathrm{~mL}$. Sedangkan untuk pembanding

JIFFK Vol. 16, No. 1, JUNI 2019, Hal. 51 - 58 
langsung dipipet sebanyak $10 \mu \mathrm{L}$. Hasil rata-rata diameter daya hambat yang diperoleh terhadap jamur Candida albicans adalah F0 $=11 \mathrm{~mm}$ termasuk kategori lemah, F1 $=14,65 \mathrm{~mm}$ dan F2 = $17,58 \mathrm{~mm}$ kategori sedang, sedangkan $\mathrm{F} 3=25,41 \mathrm{~mm}$ dan sediaan pembanding $=23,98 \mathrm{~mm}$ dikategorikan kuat. Kategori lemah, sedang dan kuat tersebut adalah pengklasifikasian respon hambatan mikroba berdasarkan Clinical and Laboratory Standard Institute (CLSI) (Cockerill dkk., 2012). Pada basis sabun cair memiliki aktivitas terhadap jamur Candida albicans karena di dalam formula terdapat sodium lauril sulfat dan propilenglikol yang bersifat bakteriostatik (Wade dan Weller, 1994).

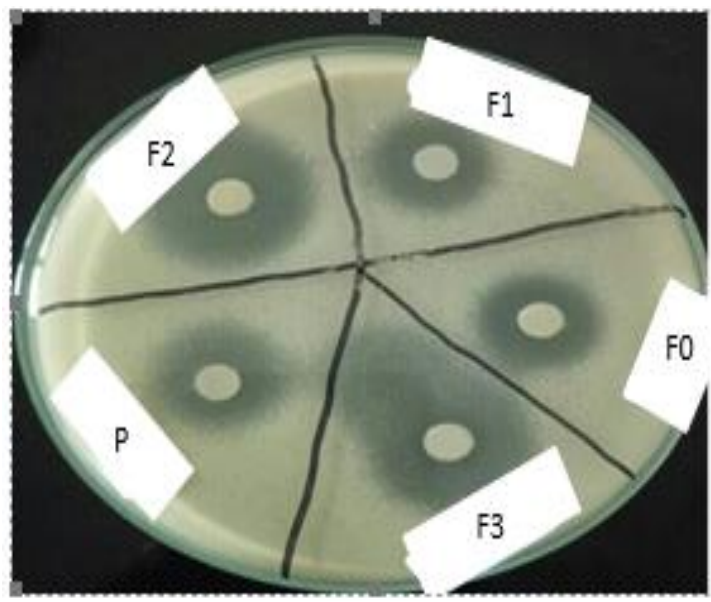

Gambar 1. Diameter daya hambat Feminime Hygiene minyak atsiri lengkuas putih

\section{KESIMPULAN}

Minyak atsiri lengkuas putih 10\%, 15\% dan 20\% dapat diformulasi dalam bentuk sabun cair antiseptik untuk feminime hygiene yang stabil secara fisik selama penyimpanan 8 minggu. Sabun cair mempunyai mempunyai aktifitas antiseptik terhadap Candida albicans kategori kuat dengan konsentrasi $20 \%$ dengan daya hambat $25,41 \mathrm{~mm}$.

\section{DAFTAR PUSTAKA}

Atmaja, H. K, 2007, Efek Antijamur Minyak Atsiri Jahe Merah (Zingiber Officinale) terhadap Candida albicans, Indonesian Journal of Dentistry.

Clayton, C, 1998, Seri Kesehatan Wanita, Keputihan dan Infeksi Jamur Candida Lain. Jakarta, Arcan.

Cockerill, F.R., Matthew A. W., Jeff. A., Michael. N.D., George. M. E., Marryy. J. F, 2012, Performance Standards for Antimicrobial Disk Susceptibility Test. Approved StandardEleventh Edition. CLSI document M02-A11. Wayne. PA. Clinical and Laboratory Standards Institute.

Departemen Kesehatan Republik Indonesia, 1979, Materia Medika Indonesi Jilid III, Direktorat Jenderal Pengawasan Obat dan Makanan, Jakarta.

Departemen Kesehatan Republik Indonesia, 1995, Farmakope Indonesia. Edisi IV, Direktorat Jendral Pengawasan Obat dan Makanan, Jakarta.

Ditjen POM, 1985, Formularium Kosmetika Indonesia, Jakarta, Departemen Kesehatan Republik Indonesia.

Djajadisastra, I, 2004, Cosmetic Stability, Departemen Farmasi Fakultas Matematika dan Ilmu Pengetahuan Alam Universitas Indonesia, Depok.

Draelos, Z.D., Lauren, A., Thaman, 2006, Cosmetic Formulation of Skin Care Product, Taylor and Francis Group, New York.

Erna, S, 2005, Pusat Penelitian dan Pengembangan Tumbuhan Obat, UNAS/P3TO UNAS.

Gaman, P.M., Sherington, K.B, 1990, Ilmu Pangan : Pengantar Ilmu Pangan, Nutrisi dan Mikrobiologi, UGM,Yogyakarta.

Guenther, E, 1987, Minyak Atsiri jilid I (Terjemahan), UI Press, Jakarta. 
Lachman, L., Lieberman, H. A., Kaning, J. L, 1994, Teori dan Praktek Farmasi Industri. UI-Press, Jakarta.

Mutmainah, Franyoto, D. Y, 2015, Formulasi dan Evaluasi Sabun Cair Ekstrak Etanol Jahe Merah ( Zingiber officinale var Rubrum) serta Uji Aktivitasnya sebagai Antikeputihan. Jurnal Fakultas Farmasi, Sekolah Tinggi Farmasi, Yayasan Pharmasi, Semarang.Hal 26-31

Pelezer, M.J., Chan, E.C.S, 1998, Dasar-dasar Mikrobiologi, UI Press, Jakarta.

Poucher, W.A, 1993, Modern Cosmestic : Perfumes, Cosmetics and Soaps, Chapman and Hall. London

Purwoko., Tjahjadi, 2010, Petunjuk Praatikum Mikrobiologi. Laboratorium Mikrobiologi UNS.

Rahmi I. W., Nurhikma E., Badia E., Ifaya M, 2017, Formulasi Sabun Pembersih Kewanitaan (Feminime Hygiene) dari Ekstrak Kulit Buah Durian (Durio zibenthinus Murray), Jurnal Mandala Phamacon Indonesia. Vol 3 No.2

Rieger, M. M, 2000, Harry's Cosmeticologi $8^{\text {th }}$ Edition. Chemical Publishing Co. Ins. New York.

Sari. R., Isadiartuti, D, 2006, Studi Aktivitas Sediaan Gel Antiseptik Tangan Ekstrak Daun Sirih(Piper Betle Linn). Jurnal Majalah Farmasi Indonesia

Siregar, R.S, 2004, Penyakit Jamur Kulit, EGC, Jakarta.

Standar Nasional Indonesia, 1996, Sabun mandi cair, Dewan Standarisasi Nasional, ICS 71.100.70, Jakarta.

Taylor, C., Lillis, C., Le, M. P, 2000, Fundamentals of nursing the art and science of nursing care $B$ Third Edition. Philadhelpia: Lippincott.

Utami., Wahyuni, D, 2010, Perbedaan Daya Hambat Ekstrak dan Perasan Rimpang Lengkuas(Alpinia galangal L.) terhadap Pertumbuhan Candida Albicans. Skripsi Program Studi Pendidikan Biologi MIPA. Jember : Fakultas Keguruan dan Ilmu Pendidikan Universitas Jember.

Wade, A., Weller, P.J, 1994, Handbook of Pharmaceutical Excipients, The Pharmaceutical Press, London.

Wasitaatmadja, S.M, 1997, Penuntun Ilmu Kosmetik, UI Press, Jakarta.

Wilkinson, J.B., dan Moore, R.J, 1982, Harry's Cosmeticology $7^{\text {th }}$ Edition. George Godwin. London

Wozniak, K. L., Floyd, L. Wormley, Jr., Paul L., Fidel, Jr, 2002, Candida Specific Antibodies during Experimental Vaginal Candidiasis in Mice, Infection and Immunity. LouisianaState University Science center, New Orleans.

JIFFK Vol. 16, No. 1, JUNI 2019, Hal. 51 - 58 